\title{
Comparing sediment DNA extraction methods for assessing organic enrichment associated with marine aquaculture
}

\author{
John K Pearman ${ }^{\text {Corresp., } 1}{ }^{1}$, Nigel B Keeley ${ }^{2}$, Susanna A Wood ${ }^{1}$, Olivier Laroche ${ }^{2}$, Anastasija Zaiko ${ }^{1,3}$, Georgia \\ Thomson-Laing ${ }^{1}$, Laura Biessy ${ }^{1}$, Javier Atalah ${ }^{1}$, Xavier Pochon ${ }^{1,3}$ \\ ${ }^{1}$ Coastal and Freshwater Group, Cawthron Institute, Nelson, New Zealand \\ 2 Institute of Marine Research in Norway, Tromsø, Norway \\ 3 Institute of Marine Science, University of Auckland, Auckland, New Zealand \\ Corresponding Author: John K Pearman \\ Email address: John.Pearman@cawthron.org.nz
}

Marine sediments contain a high diversity of micro- and macro-organisms which are important in the functioning of biogeochemical cycles. Traditionally, anthropogenic perturbation has been investigated by identifying macro-organism responses along gradients. Environmental DNA (eDNA) analyses have recently been advocated as a rapid and cost-effective approach to measuring ecological impacts and efforts are underway to incorporate eDNA tools into monitoring. Before these methods can replace or complement existing methods, robustness and repeatability of each analytical step has to be demonstrated. One area that requires further investigation is the selection of sediment DNA extraction method. Environmental DNA sediment samples were obtained along a disturbance gradient adjacent to a Chinook (Oncorhynchus tshawytscha) salmon farm in Otanerau Bay, New Zealand. DNA was extracted using four extraction kits (Qiagen DNeasy PowerSoil, Qiagen DNeasy PowerSoil Pro, Qiagen RNeasy PowerSoil Total RNA/DNA extraction/elution and Favorgen FavorPrep Soil DNA Isolation Midi Kit) and three sediment volumes $(0.25 \mathrm{~g}, 2 \mathrm{~g}$, and $5 \mathrm{~g})$. Prokaryotic and eukaryotic communities were amplified using primers targeting the $16 \mathrm{~S}$ and $18 \mathrm{~S}$ ribosomal RNA genes, respectively, and were sequenced on an Illumina MiSeq. Diversity and community composition estimates were obtained from each extraction kit, as well as their relative performance in established metabarcoding biotic indices. Differences were observed in the quality and quantity of the extracted DNA amongst kits with the two Qiagen DNeasy PowerSoil kits performing best. Significant differences were observed in both prokaryotes and eukaryotes $(p<0.001)$ richness among kits. A small proportion of amplicon sequence variants (ASVs) were shared amongst the kits $(\sim 3 \%)$ although these shared ASVs accounted for the majority of sequence reads (prokaryotes: $59.9 \%$, eukaryotes: $67.2 \%$ ). Differences were observed in the richness and relative abundance of taxonomic classes revealed with each kit. 
Multivariate analysis showed that there was a significant interaction between 'distance' from the farm and ' $k i t$ ' in explaining the composition of the communities, with the distance from the farm being a stronger determinant of community composition. Comparison of the kits against the bacterial and eukaryotic metabarcoding biotic index suggested that all kits showed similar patterns along the environmental gradient. Overall, we advocate for the use of Qiagen DNeasy PowerSoil kits for use when characterizing prokaryotic and eukaryotic eDNA from marine farm sediments. We base this conclusion on the higher DNA quality values and richness achieved with these kits compared to the other kits/amounts investigated in this study. The additional advantage of the PowerSoil Kits is that DNA extractions can be performed using an extractor robot, offering additional standardization and reproducibility of results. 


\section{Comparing sediment DNA extraction methods for assessing organic} 2 enrichment associated with marine aquaculture

3

4

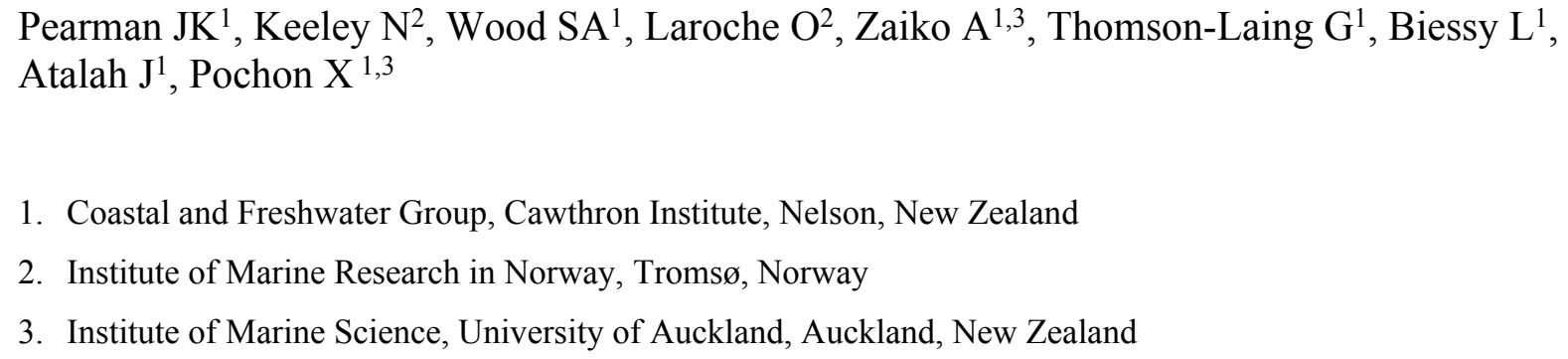

\section{Abstract}

Marine sediments contain a high diversity of micro- and macro-organisms which are important in the functioning of biogeochemical cycles. Traditionally, anthropogenic perturbation has been investigated by identifying macro-organism responses along gradients. Environmental DNA (eDNA) analyses have recently been advocated as a rapid and cost-effective approach to measuring ecological impacts and efforts are underway to incorporate eDNA tools into monitoring. Before these methods can replace or complement existing methods, robustness and repeatability of each analytical step has to be demonstrated. One area that requires further investigation is the selection of sediment DNA extraction method.

Environmental DNA sediment samples were obtained along a disturbance gradient adjacent to a Chinook (Oncorhynchus tshawytscha) salmon farm in Otanerau Bay, New Zealand. DNA was extracted using four extraction kits (Qiagen DNeasy PowerSoil, Qiagen DNeasy PowerSoil Pro, Qiagen RNeasy PowerSoil Total RNA/DNA extraction/elution and Favorgen FavorPrep Soil DNA Isolation Midi Kit) and three sediment volumes ( $0.25 \mathrm{~g}, 2 \mathrm{~g}$, and $5 \mathrm{~g})$. Prokaryotic and eukaryotic communities were amplified using primers targeting the $16 \mathrm{~S}$ and $18 \mathrm{~S}$ ribosomal RNA genes, respectively, and were sequenced on an Illumina MiSeq. Diversity and community 
35 composition estimates were obtained from each extraction kit, as well as their relative

36 performance in established metabarcoding biotic indices.

38 Differences were observed in the quality and quantity of the extracted DNA amongst kits with

39 the two Qiagen DNeasy PowerSoil kits performing best. Significant differences were observed in

40 both prokaryotes and eukaryotes $(\mathrm{p}<0.001)$ richness among kits. A small proportion of

41 amplicon sequence variants (ASVs) were shared amongst the kits $(\sim 3 \%)$ although these shared

42 ASVs accounted for the majority of sequence reads (prokaryotes: 59.9\%, eukaryotes: 67.2\%).

43 Differences were observed in the richness and relative abundance of taxonomic classes revealed with each kit. Multivariate analysis showed that there was a significant interaction between 'distance' from the farm and 'kit' in explaining the composition of the communities, with the distance from the farm being a stronger determinant of community composition. Comparison of the kits against the bacterial and eukaryotic metabarcoding biotic index suggested that all kits showed similar patterns along the environmental gradient. Overall, we advocate for the use of Qiagen DNeasy PowerSoil kits for use when characterizing prokaryotic and eukaryotic eDNA from marine farm sediments. We base this conclusion on the higher DNA quality values and richness achieved with these kits compared to the other kits/amounts investigated in this study.

52 The additional advantage of the PowerSoil Kits is that DNA extractions can be performed using an extractor robot, offering additional standardization and reproducibility of results. 
66

67

68

69

\section{Introduction}

Marine sediments harbor diverse biological communities that are vital in maintaining biogeochemical cycles, food webs and ecosystem functioning. However, these communities can be significantly impacted by anthropogenic activities (Snelgrove, 1997; Dell'Anno et al., 2003). Studies assessing the effects of human induced perturbations on the benthic environment have traditionally involved the analysis of communities of macro-organisms (Papageorgiou, Sigala \& Karakassis, 2009; Keeley, Forrest \& Macleod, 2013; Aguado-Giménez et al., 2015). Micro- and meio-benthic organisms have received less attention partly due to the challenges associated with morphologically identifying the immense diversity of these organisms. Developments in environmental genomics now allow communities to be more accurately characterized. These techniques are currently being touted as cost-effective and sensitive methodologies to monitor entire biological communities in marine sediments, especially along gradients of anthropogenic disturbances (Pawlowski et al., 2016b; Laroche et al., 2016, 2018; Aylagas et al., 2017; Borja, 2018; Keeley, Wood \& Pochon, 2018; Cordier, 2020).

Environmental genomic techniques, which enable a broad range of taxonomic groups to be characterized from environmental DNA (eDNA), have become more prevalent in the last decade (Taberlet et al., 2018). The DNA in these samples originates from a combination of microbes, organisms body parts or cells contained in faeces, epidermal mucus, urine, saliva and gametes of larger organisms (Rees et al., 2014; Taberlet et al., 2018). While eDNA-based techniques (e.g. metabarcoding) are now used extensively in ecological studies (Bohmann et al., 2014), they are also considered for routine biomonitoring purposes (Aylagas et al., 2020). The delay in their incorporation into monitoring regimes is due, in part, to the need for each step of the process (e.g. sediment collection, DNA extraction, PCR amplification, etc.) to be demonstrated as robust and repeatable (Darling et al., 2020).

Environmental DNA methodologies have the potential for monitoring of a variety of disturbance gradients but an eDNA application that is close to uptake and implementation is the use of metabarcoding for monitoring benthic impacts of fish farming (Aylagas et al., 2020). Sea-cagebased fish farms are inevitably associated with elevated fluxes of organic waste, often 
97 culminating in severe localized benthic enrichment (i.e. anoxic and azoic conditions directly

98 beneath the farms), which gradually decreases with distance from the fish cages (Brooks \&

99 Mahnken, 2003a,b). Routine monitoring of the benthic environment is usually required by

100 regulation and traditional monitoring methods typically involve measuring the chemical

101 properties of sediment and microscopic analysis of macrofaunal diversity (Keeley, Macleod \&

102 Forrest, 2012). In New Zealand for example, these parameters are incorporated into an

103 Enrichment Stage (ES) index (Keeley, Macleod \& Forrest, 2012; Keeley et al., 2012; MPI,

104 2018), which provides regulators and producers with an integrated, weight-of-evidence-based

105 measure of environmental impact. Morphological approaches, however, are often time-

106 consuming, expensive, and require a high level of taxonomic expertise that is shrinking globally

107 (Jones, 2008). These limitations have led to numerous metabarcoding investigations describing

108 the ecological responses of a wide range of organisms associated with enrichment states,

109 including bacteria (Fodelianakis et al., 2015; Dowle et al., 2015; Verhoeven et al., 2018; Stoeck

110 et al., 2018a), foraminifera (He et al.; Pawlowski et al., 2014, 2016a; Pochon et al., 2015),

111 ciliates (Stoeck et al., 2018b), metazoans (Lejzerowicz et al., 2015), or a combination of multi-

112 trophic taxa (Keeley, Wood \& Pochon, 2018; Frühe et al., 2020). Although all of these studies

113 have revealed consistent organismal responses to fish farm enrichment, indicating that

114 metabarcoding is a cost-effective tool for routine monitoring, they have all used different

115 sediment collection methods, varying amounts of starting material (from $0.25 \mathrm{~g}$ to $10 \mathrm{~g}$ of

116 sediment), and a variety of DNA extraction kits. The succesful uptake of metabarcoding tools for

117 commercial monitoring of fish farms requires a fully standardized and validated laboratory

118 workflow. There is a need to evaluate the effects that DNA extraction methods have on the

119 detection of bioindicator taxa and the entire community diversity.

121 One of the complexities with analysis of sediment samples is that they are remarkably variable in

122 chemical composition and physical properties across spatial scales. This variability can have an

123 impact on the absorption of eDNA, with clays and humic acids having a strong binding capacity

124 for DNA molecules (Dell'Anno, Stefano \& Danovaro, 2002). Other factors such as temperature

125 and porewater $\mathrm{pH}$ have an impact on the retention and stability of DNA (Levy-Booth et al.,

126 2007; Torti, Lever \& Jørgensen, 2015). This has led to a multitude of specific protocols that aim

127 to optimize the extraction process for different sediment types (Kallmeyer \& Smith, 2009; 
128 Morono et al., 2014; Lever et al., 2015). These methods rely on disrupting the cell membranes by

129 either physical (e.g. bead-beating, freeze-thaw; MacGregor et al., 1997; Haile, 2012; Pearman et

130 al., 2016), chemical (e.g. solvents; Pitcher, Saunders \& Owen, 1989) or enzymatic (Holben et al.,

131 1988) means. More recently, commercial DNA extraction kits have been used as an alternative to

132 manual extraction protocols (Lear et al., 2018). There are drawbacks to commercial kits in that

133 the protocols are often inflexible and the reagents are proprietary, but they streamline the often-

134 laborious task of manual extracts and tend to avoid the use of organic solvents (Lever et al., 135 2015).

136

137 Previous research has shown that the quantity and quality of the extracted DNA can vary

138 between methods (Knauth, Schmidt \& Tippkötter, 2013; Lekang, Thompson \& Troedsson, 2015;

139 Hermans, Buckley \& Lear, 2018; Armbrecht et al., 2020). Extraction methods have also been

140 shown to affect detected bacterial composition with various phyla being either over or under

141 represented (Luna, Dell'Anno \& Danovaro, 2006; Carrigg et al., 2007; Holmsgaard et al., 2011;

142 Lekang, Thompson \& Troedsson, 2015; Hermans, Buckley \& Lear, 2018). This has important

143 implications for molecular-based biomonitoring, as results need to be comparable spatially and

144 temporally, and should be repeatable and provide a true representation of the community in a

145 sample. The majority of benthic marine studies that have targeted both prokaryotic and

146 eukaryotic organisms have typically used kits that necessitate $>2 \mathrm{~g}$ of sediment for DNA

147 extraction (Lear et al., 2018). If the same results can be obtained with smaller volumes of starting

148 material, then this will allow the extraction process to be automated (e.g. using a sample prep

149 robot), which would standardize and greatly expedite the process and make it more cost-effective

150 for routine monitoring.

151

152 The sampling described in this study was part of a long term (8 years) research project, which

153 aimed to validate a metabarcoding-based protocol for assessing and monitoring the benthic

154 impacts of salmon farming in New Zealand (Pochon et al., 2020). While interesting ecological

155 inferences can be gained from studying impact gradients around fish farms those results will be

156 presented elsewhere. The current study focusses on the first step in the workflow optimization

157 process by investigating the effect of DNA extraction kits and sediment quantities on prokaryotic

158 and eukaryotic assemblages along an organic enrichment gradient adjacent to fish farms. The 
159 null hypothesis of the experiment was that distinct extraction kits and sediment quantities would

160 not affect the quality or quantity of extracted DNA, detected prokaryotic and eukaryotic

161 assemblages, and therefore - metabarcoding-based benthic health assessment.

162

\section{Methods}

164

165 Sediment eDNA samples were collected in November 2015 as part of a regular compliance 166 monitoring program for New Zealand King Salmon (NZKS) at a Chinook (Oncorhynchus 167 tshawytscha) salmon farm located in Otanerau Bay (41 ${ }^{\circ} 10^{\prime} 11^{\prime}$ 'S, $\left.174^{\circ} 19^{\prime} 16^{\prime \prime} \mathrm{E}\right)$, Marlborough

168 Sounds, New Zealand (Figure 1). The farm location is characterized as a 'low flow' area, having 169 a mean current velocity of approximately $6 \mathrm{~cm} \mathrm{~s}^{-1}$ and a water depth of 34-35 m. Sampling 170 started directly alongside the pen and radiated outwards along an enrichment gradient with 171 samples collected at 50 and $150 \mathrm{~m}$, and at a control site located $625 \mathrm{~m}$ from the farm. Bulk 172 sediment at each side was collected using a Van-Veen grab with sediment biogeochemical 173 properties at each station in Table S1. Three distinct surface-sediment samples (c. 40 g per grab) 174 were collected from the top 1-2 $\mathrm{cm}$ of each grab surface using a sterile spatula and placed in $175 \mathrm{DNA} / \mathrm{RNAse}-$ free collection tubes $(50 \mathrm{~mL})$. Sediment samples were immediately placed on ice 176 and transported to the Cawthron laboratory where they were stored at $-80^{\circ} \mathrm{C}$ until DNA 177 extraction.

178

179 Each step of the following molecular analyses was conducted in separate sterile laboratories 180 dedicated to these steps, with sequential workflow to ensure no cross-contamination. Rooms 181 dedicated to DNA extraction, amplification set-up and template addition were equipped with 182 laminar flow cabinets with HEPA filtration and room-wide ultra-violet sterilization which was 183 switched on for $>15 \mathrm{~min}$ before and after each use. Aerosols barrier tips (Axygen, CA, USA) 184 were used throughout.

185

186 Each of the 12 sediment samples were homogenized using sterile stainless steel grinding beads in 187 the $1600 \mathrm{MiniG}^{\circledR}$ tissue homogenizer (1,500 RPM, $2 \mathrm{~min}$ ). From these homogenized samples 188 five sub-samples representing three distinct sediment volumes $(0.25 \mathrm{~g}, 2 \mathrm{~g}$, and $5 \mathrm{~g})$ were 
189 extracted using four DNA extraction kits (Table 1). Amongst the many kits available on market,

190 we selected these four specific kits for the following reasons. Qiagen Power Soil kits (Q.PS and

191 Q.PS.Pro) integrates a patented Inhibition Removal Technology ${ }^{\circledR}$ that works particularly well for

192 eDNA isolation from challenging samples such as enriched soils. This likely explains why the

193 majority of soil eDNA studies use Qiagen kits (Lear et al., 2018) and justifies our emphasis on

194 Qiagen Power Soil kits in this study. Second, the Qiagen RNeasy PowerSoil Total RNA/DNA

195 extraction/elution kit (QIA2) is the most commonly used kit in previous fish farm studies

196 (Pawlowski et al., 2014; Dowle et al., 2015; Lejzerowicz et al., 2015; Pochon et al., 2015;

197 Keeley, Wood \& Pochon, 2018), but this DNA/RNA co-extraction protocol is comparatively

198 very time-consuming and involves dangerous chemicals such as phenol-chloroform. Third, to

199 our knowledge there are only two commercial soil kits that allow extraction of up to $10 \mathrm{~g}$ of

200 material, the Qiagen PowerMax Soil kit and the Favorgen Soil Midi-prep kit (Young et al.,

201 2014). Cost-considerations are essential for routine monitoring, and therefore we chose to test

202 the latter kit, being significantly cheaper than the former kit. DNA was extracted using a

203 QIAcube automated sample prep robot (Qiagen Instruments, Switzerland) for the Qiagen

204 DNeasy PowerSoil Kit (Q.PS) and Qiagen DNeasy PowerSoil Pro Kit (Q.PS.Pro) kits, while

205 extraction was done manually for the remaining kits, according to the manufacturer's

206 instructions. The quality and purity of isolated DNA were measured using a Nanophotometer

207 NP80 (Implen, Munich, Germany). This instrument is equipped with an automatic quality

208 control software that enables the detection of impurities and/or air bubbles within extracted

209 samples.

210

211 Polymerase chain reactions (PCR) were performed on all extracted samples $(n=60)$ and targeted

212 two genes. Prokaryotic communities were amplified using a 16S rRNA gene (V3-V4 region)

213 with the primer set 341F: 5'-CCT ACG GGN GGC WGC AG-3' (Herlemann et al., 2011) and

214 805R: 5'-GAC TAC HVG GGT ATC TAA TCC-3' (Klindworth et al., 2013). Eukaryotic

215 communities were targeted using the primer set Uni18SF: 5'- AGG GCA AKY CTG GTG CCA

216 GC-3' and Uni18SR: 5'-GRC GGT ATC TRA TCG YCT T-3' (Zhan et al., 2013), which

217 amplified the 18S rRNA gene (V4 region). Both the prokaryotic and eukaryotic primers had an

218 Illumina overhang adapter present as per the Illumina 16S library preparation manual.

219 Amplifications were undertaken in an Eppendorf Mastercycler (Eppendorf, Hamburg, Germany) 
220 in a total volume of $50 \mu \mathrm{L}$ using $\mathrm{MyFi}^{\mathrm{TM}}$ PCR Master Mix (Bioline Meridian Bioscience), $2 \mu \mathrm{L}$

221 of each primer (10 $\mu \mathrm{M}$ stock) and $2 \mu \mathrm{L}$ of template eDNA. The PCR cycles for the $16 \mathrm{~S}$ rRNA

222 gene amplification were as follows: $95^{\circ} \mathrm{C}$ for $5 \mathrm{~min}$ followed by 35 cycles of $94{ }^{\circ} \mathrm{C}(30 \mathrm{~s}), 54{ }^{\circ} \mathrm{C}$

$223(30 \mathrm{~s})$ and $72{ }^{\circ} \mathrm{C} \mathrm{(45} \mathrm{s)} \mathrm{with} \mathrm{a} \mathrm{final} \mathrm{extension} \mathrm{at} 72{ }^{\circ} \mathrm{C}$ for $7 \mathrm{~min}$. Amplifications for the $18 \mathrm{~S}$

224 rRNA gene were $95{ }^{\circ} \mathrm{C}$ for 5 min followed by 37 cycles of: $94{ }^{\circ} \mathrm{C}(30 \mathrm{~s}), 54{ }^{\circ} \mathrm{C}(30 \mathrm{~s})$ and $72{ }^{\circ} \mathrm{C}$

225 (45 s) with a final extension at $72{ }^{\circ} \mathrm{C}$ for $7 \mathrm{~min}$. Negative PCR controls were included in each

226 PCR run. Amplicon PCR products were purified using AMPure $\mathbb{R}$ XP PCR Purification beads

227 (Agencourt ${ }^{\circledR}$, MA, USA) and quantified using a Qubit ${ }^{\circledR}$ Fluorometer (Life Technologies,

228 Carlsbad, CA, USA). An additional water control was added to test for potential contamination

229 during the following sequencing workflow. All negatives were subsequently sequenced. Products

230 ( $\mathrm{n}=68 ; 60$ samples plus 5 PCR blanks and 3 water blanks) were diluted $\left(3 \mathrm{ng} \mu \mathrm{L}^{-1}\right)$ and sent to

231 Auckland Genomics (University of Auckland) for final library construction. Dual indices were

232 added to the amplicons via a second round of PCR amplification as detailed in the Illumina 16S

233 library preparation manual. Subsequent to the second round of amplification, $5 \mu \mathrm{L}$ of each

234 sample (including all controls) was pooled and a single clean-up was undertaken. A bioanalyzer

235 was used to check the quality of the library which was then diluted $4 \mathrm{nM}$ and denatured. The

236 library was diluted to a final loading concentration of $7 \rho \mathrm{M}$ with a $15 \%$ spike of PhiX. Paired-

237 end sequences ( 2 × 250 bp) were generated on an Illumina MiSeq instrument. Raw sequences

238 were deposited in the NCBI short read archive under accession: PRJNA657189

239

240 Reads were demultiplexed using the MiSeq Reporter (v2) based on the Nextera ${ }^{\mathrm{TM}}$ dual-indexing.

241 Primers were removed from the sequences using cutadapt (version 1.8; (Martin, 2011), allowing

242 a maximum error rate of 0.1. Sample reads were processed using the DADA2 program (Callahan

243 et al., 2016) implemented in QIIME2 version 2018.11 (Bolyen et al., 2019) using default

244 parameters. The reads were truncated at 228 and $216 \mathrm{bp}$ for the forward and reverse $16 \mathrm{~S}$ rRNA

245 gene sequences, and 225 and $216 \mathrm{bp}$ for the 18S rRNA gene sequences, and the maxEE value

246 (expected error rate) was set to 20. The sequences were merged into Amplicon Sequence

247 Variants (ASVs) with a minimum overlap of $10 \mathrm{bp}$ and no mismatches. Chimeras were detected

248 and removed using the removeBimeraDenovo script in DADA2. Taxonomic assignments were

249 undertaken in DADA2 based on the rdp (Wang et al., 2007) algorithm against the SILVA 132

250 database (Pruesse et al., 2007). In the prokaryotic dataset, ASVs assigned to eukaryotes, 
251 chloroplasts and mitochondria were removed prior to further analysis. Code for the analysis can

252 be found at: https://github.com/olar785/Optimizing-DNA-extraction-methods-for-assessing-

253 organic-enrichment-in-marine-farm-sediments/blob/master/Q2 DADA2 pipeline.sh and the

254 taxonomy for each ASV sequence can be found in Table S2.

255

256 The output from DADA2 was imported into phyloseq (McMurdie \& Holmes, 2013) within R

257 software (R Core Team, 2020). To remove possible contamination from the data we used the

258 maximum sequence count for each ASV present in the controls as a basis for subtraction (Bell et

259 al., 2019). Thus, any ASV in the dataset with fewer reads than found in the controls was assumed

260 to be contamination and removed from analysis. ASVs that had read numbers higher than the

261 threshold had their read counts reduced by the threshold number to take into account the

262 contamination. To allow comparison between samples, rarefaction plots were constructed with

263 ggrare (Kandlikar et al., 2018) and ggplot2 (Wickham, 2016) and subsequently reads were

264 subsampled to 4,400 per sample for prokaryotes and 10,000 per sample for eukaryotes (Figure

265 S1). Richness values were tested for normality (shapiro.test) and homogeneity of variance

266 (bartlett.test) and subsequently a square root transformation was undertaken to meet these

267 assumptions. Differences in richness (square root transformed) were assessed using two-way

268 analysis of variance (ANOVA), with kit (5 levels) and distance (4 levels) as factors. Pairwise

269 post-hoc tests were undertaken using the Tukey Honestly Significant Difference (HSD) test.

270 Shared ASVs were assessed in phyloseq and plotted with VennDiagram (Chen \& Boutros,

271 2011).

272

273 Multivariate analysis was undertaken on both datasets using the rarefied samples. Non-metric

274 multidimensional scaling (nMDS) was undertaken to visualize the 2D representation of the

275 community structure. Statistical differences were tested using permutational multivariate analysis

276 of variance (PERMANOVA, (Anderson, Gorley \& Clarke, 2008)) based on Bray- Curtis

277 dissimilarities of the square root transformed data using PRIMER (Anderson, Gorley \& Clarke,

278 2008). The experimental design consisted of two crossed factors: Kit and Distance; five levels

279 for factor Kit (Q.PS, Q.PS.Pro, QIA2, FAV2 and FAV5) and 4 levels for Distance (Pen, 50 m,

$280150 \mathrm{~m}$ and Control). To assess the taxonomic composition of the communities, ASVs were

281 merged at class level. To assess the effect of kit on benthic health assessments the denovo 
282 indices, the bacterial Metabarcoding Biotic Index (b-MBI) and the eukaryotic Metabarcoding

283 Biotic Index (e-MBI) were calculated using pre-defined molecular Eco-Groups at the ASV level

284 following Keeley, Wood and Pochon (2018). Figures were constructed in R using the package

285 ggplot2 (Wickham, 2016) and ampvis2 (Andersen et al., 2018).

286

287 Code for the statistical analysis can be found at:

288 https://github.com/jkpearmanbioinf/FishFarmAnalysis/blob/master/KitComparison.notebook.Rm

$289 \underline{\text { d }}$

290

291 Results

292 DNA quality was generally highest for samples extracted with the Q.PS kit (Table S3). The

293 Q.PS.Pro kit yielded similar albeit more scattered absorbance values, and a lower overall DNA

294 concentration compared to the Q.PS kit. Both the QIA2 and the FAV2 kits had low A260/A230

295 ratios indicating contamination by compounds that absorb in the A230 range (e.g.

296 Ethylenediaminetetraacetic acid (EDTA), carbohydrates). The FAV5 and QIA2 kits yielded the

297 highest overall DNA concentration estimates, although they failed most of the automatic quality

298 controls (Table S3). Lower DNA concentrations after PCR cleanup were noted for the FAV2,

299 FAV5 and QIA2 kits in the eukaryotic samples compared with the Q.PS and Q.PS.Pro kits

300 (Table S3).

301

302 High-Throughput Sequencing resulted in a total of 3,337,510 prokaryotic sequences $(915,508$ after

303 filtering; Table S4) and 6,318,916 eukaryotic sequences (4,382,737 after filtering; Table S4).

304 Replicates for FAV2 at $150 \mathrm{~m}$ for the prokaryotic dataset were removed from the dataset as they

305 did not meet the rarefaction thresholds. Following bioinformatics analyses using DADA2, a total

306 of 14,427 and 11,177 ASVs were identified for prokaryotic and eukaryotic communities,

307 respectively.

308

309 There was a statistical difference in the observed richness amongst kits for the eukaryotic ( $\mathrm{F}=$

$3107.442, \mathrm{p}<0.001)$ dataset, while there was a significant interaction in the prokaryotic dataset $(\mathrm{F}=$

$3117.575 ; \mathrm{p}<0.001)$. Pairwise tests showed that there was has a higher diversity retrieved in the

312 Q.PS and Q.PS.Pro kits in the pen compared with other kits in the prokaryotic dataset (Figure 
313 2A) with the majority of the other comparisons were non-significant. The FAV2 kit had a

314 significantly lower diversity than the other kits in the eukaryotic dataset (Figure 2B). Similar

315 trends were observed when investigating the Shannon diversity for the prokaryotes $(\mathrm{F}=13.87, \mathrm{p}$

$316<0.001$, Figure S2). There was a significant trend for the eukaryotes $(F=2.723, p=0.039$,

317 Figure S2) although no pairwise comparisons were significant.

318

319 Only a small proportion of the ASVs were shared amongst all kits (prokaryotes: 3.5\%

320 eukaryotes: 3.2\%), however these shared ASVs accounted for $59.9 \%$ of prokaryotic and $67.1 \%$

321 of eukaryotic reads (Figure 3). This indicates that the majority of the ASVs that are not shared

322 are of low abundance. In the prokaryotic dataset, the Q.PS.Pro kit had the greatest proportion of

323 unique (not observed in any other kit) ASVs accounting for $66.5 \%$ of the total prokaryotic

324 diversity retrieved by the kit (Figure 3A). The lowest proportion of unique ASVs was observed

325 in the FAV5 (43.9\%) and FAV2 (44.3\%) kits for the prokaryotic dataset. For the eukaryotic

326 dataset, all kits had a similar number of unique ASVs, ranging from 51\% in the Q.PS.Pro kit to

$32756.2 \%$ in the QIA2 kit (Figure 3B).

328

329 In general, all kits detected the same dominant classes of both prokaryotes and eukaryotes.

330 However, the relative abundance of these groups differed when all distances from the farm were

331 combined (Figure 4, Figure S3). The dominant prokaryotic class Bacteroidia yielded similar

332 percentages of read abundances across all kits (Figure 4A). Nonetheless, there were differences

333 at the family level, with Flavobacteriaceae having lower relative abundances in the Q.PS (12.2\%)

334 and Q.PS.Pro (7.4\%) kits compared with the other kits (FAV2: 24.7\%; FAV5:18.7\% and QIA2:

335 22.1\%) while Bacteroidetes BD2-2 had higher relative abundances in these kits (Q.PS: 9\% and

336 Q.PS.Pro: 8.3\%) than the others (FAV2: 3.7\%; FAV5:3.4\% and QIA2: 3.7\%). Campylobacteria

337 was the second most abundant class across kits except for the Q.PS and Q.PS.Pro kits (Figure

338 4A). Fusobacteria and Deltaproteobacteria had higher relative abundances in the Q.PS and

339 Q.PS.Pro kits compared with the other three kits. Differences in the relative abundance of reads

340 in the eukaryotic dataset was more variable at the class level between kits (Figure 4B). The

341 apicomplexan class Conoidasida had a higher relative read abundance in the FAV2 and FAV5

342 kits and was especially low in the Q.PS kit. In contrast, Chromadorea (Nematoda), was lower in

343 these kits (FAV2 and FAV5) compared with the other kits especially Q.PS and Q.PS.Pro (Figure 
344 4B). While ASVs belong to fish were not a substantial proportion of the dataset they were

345 detected as would be expected with higher read numbers underneath the pens. Furthermore, there

346 were differences in the number of ASVs found per class across kits in both the 16S rRNA and

347 18S rRNA gene datasets (Table S5 and S6, respectively).

348 Similar patterns were observed for the community structure (Figure 5) amongst kits with

349 distance from the farm (i.e. decrease in organic enrichment levels) being a stronger determinant

350 than kit. Strong and consistent clustering of replicate samples and kits were observed amongst

351 collection sites, from highly enriched sediments adjacent to fish farm pens through to the un-

352 enriched control sites, particularly in the prokaryotic dataset (Figure 5A). Although similar

353 patterns were observed for eukaryotes, the clusters appeared to be more diffused compared to

354 prokaryotes (Figure 5B). Both the prokaryote $(\mathrm{F}=1.71 ; \mathrm{p}<0.001)$ and eukaryote $(\mathrm{F}=1.36 ; \mathrm{p}<$

355 0.001) PERMANOVA results confirmed that there was significant interaction between kits and

356 distance (Table S7). Pairwise comparisons indicated that at each distance there was no

357 significant difference amongst kits (with 3 exceptions; see Table S7). For factor kit pairwise

358 comparisons indicated that the Q.PS and Q.PS.Pro kits were better at differentiating the

359 environmental gradient with pairwise comparisons significantly different amongst distances for

360 these two kits (Table S7).

361

362 The bacterial Metabarcoding Biotic Index (b-MBI) and eukaryotic Metabarcoding Biotic Index (e-

$363 \mathrm{MBI}$ ) were calculated and multivariate analysis on the weighted abundances of the five eco-groups

364 was undertaken. Multivariate analysis indicated strong and consistent clustering of replicates and

365 samples from different kits for each distance along the gradient especially in for the b-MBI (Figure

366 6). PERMANOVA results indicated that there were significant differences for in the $b-\mathrm{MBI}(\mathrm{F}=$

367 13.22; $\mathrm{p}<0.001)$ and e-MBI $(\mathrm{F}=4.54 ; \mathrm{p}=0.002)$ with kit. However, pairwise comparisons showed

368 no significant differences. For distance there were significant differences in both the b-MBI (F=

369 421.08; $\mathrm{p}<0.001)$ and e-MBI $(\mathrm{F}=64.33 ; \mathrm{p}<0.001)$ with all distances being significantly different.

370

371 Discussion

372 For molecular methods to be used reliably in monitoring potential degradation of benthic

373 habitats, samples should be representative of the targeted community and the DNA sufficiently

374 pure to ensure that inhibitors do not affect the analysis (McKee, Spear \& Pierson, 2015). The use 
375 of DNA extraction kits is highly desirable as it standardizes this process and, in some instances,

376 allows the automatization of extraction using robotics. The aim of the study was to explore how

377 the application of four different extraction kits (all commonly used in soil/sediment studies)

378 impacted the composition and structure of prokaryotic and eukaryotic communities in marine

379 surface sediments derived via metabarcoding. In addition, with each kit allowing different

380 amounts of starting material, three different weights of sediment were used (two different

381 weights were tested for the Favorgen kit).

382

383 We used benthic sediment samples along an enrichment gradient associated to salmon farms as a

384 study case, and investigated the quantity and quality of DNA extracted using five different

385 extraction kits. In general, the three kits using higher volumes of sediment (QIA2, FAV2 and

386 FAV5) retrieved higher concentrations of eDNA. However, this higher quantity of DNA was

387 often offset with a lower overall quality, with the Q.PS and Q.PS.Pro kits having the largest

388 number of samples that passed the automatic quality control on the nanophotometer. The QIA2

389 and FAV2 kits had comparatively low A260/A230, indicating potential contaminants such as

390 humic compounds which absorb in the A230 spectrum (Yeates et al., 1998). The presence of

391 humic acids in sediment samples is a known concern as it can complex with DNA (Lakay, Botha

392 \& Prior, 2007) and interfere with subsequent PCR amplification. DNA from all samples was

393 successfully amplified, although PCRs were noted to be less efficient for the kits using higher

394 volumes, indicating that the potential contaminants did not inhibit PCR reactions completely but

395 further studies would be required to assess what was causing the low A260/230 ratios.

396

397 We expected that the higher weights of sediment would result in a higher diversity of ASVs.

398 However, the kits using higher starting weights of sediment (QIA2, FAV2 and FAV5) in general

399 revealed lower prokaryotic diversity than the Q.PS and Q.PS.Pro kits, although the significance

400 of these results varied and, except for FAV2, were not observed for the eukaryotes. The lack of

401 correlation between starting material and diversity has previously been reported by Carrigg et al.,

402 (2007). The current study assessed two weights using the same kit for the Favorgen kit only, and

403 found no significant difference in the richness between weights. However, further studies using a

404 variety of kits and more weights would be required to confirm this trend. Inefficiencies in the

405 extraction kits using large sediment weights could explain this observation with the possibility 
406 that humic acids and other contaminants are binding to the silica filters and reducing the 407 concentration of DNA bound to the filters (Lloyd, Macgregor \& Teske, 2010). If the latter 408 hypothesis is true, then the obvious limitation is that research practitioners aiming to 409 appropriately capture micro-patchiness and/or spatial heterogeneity of biological assemblages 410 (i.e. beta diversity) in marine sediments, will have to adapt their sampling size accordingly. For 411 this reason, previous fish farm studies have advocated for the collection of at least 3 to 5 412 independent replicate samples per station (Pawlowski et al., 2014; Lejzerowicz et al., 2015; 413 Pochon et al., 2015). In this respect, the detection of higher diversity in the Q.PS and Q.PS.Pro 414 kits has a further advantage as the small volumes used in the Q.PS and Q.PS.Pro kits mean 415 samples can be processed using automated equipment (e.g. QIAcube, Qiagen). The automated 416 methodologies limit the human involvement (i.e., variability) in the procedure and are thus

417 beneficial for monitoring purposes where replicability is vital.

418

419 Only a small percentage of ASVs were shared between all kits in both the prokaryotic and 420 eukaryotic datasets. However, these shared ASVs accounted for a substantial (i.e. $>60 \%$ ) portion 421 of the total number of reads. This suggests that all kits are detecting the core communities and 422 that the main differences in detection are in rare and low abundance ASVs, as has been shown in 423 previous environmental metabarcoding studies (Pedros-Alio, 2006; Lynch \& Neufeld, 2015). It 424 should be noted that while PCR and sequencing controls were undertaken to detect potential 425 contamination in those steps, no extraction controls were used in this experiment. Therefore, we 426 cannot exclude the possibility that a small proportion of the shared ASVs recovered here are due 427 to residual contamination from kits or equipment, and extraction controls should be sequenced in 428 future studies to evaluate this possibility. The higher number of unique ASVs in the Q.PS and 429 Q.PS.Pro kits could suggest that these kits are able to retrieve a larger number of rare ASVs. 430 However, this may also, in part, be due to stochastic differences in eDNA distribution within 431 sediments rather than extraction differences. The rare ASVs could possibly be found with all kits 432 if increased sequencing depth or further replication (either extraction or PCR replicates) were 433 undertaken. Previous research has shown that increasing replication can give a more reliable 434 estimation of diversity (Lanzén et al., 2017). Kits that require fewer replicates to retrieve a 435 similar diversity are likely to be more cost efficient and thus more suitable for high throughput 
436 monitoring applications. These data indicate that the Q.PS and Q.PS.Pro kits provide the best

437 estimation of prokaryotic and eukaryotic community diversity.

438

439 Multivariate analysis indicated that while there was a significant interaction between kit and

440 distance from the pens, all the kits showed a similar pattern with different communities along the

441 transect. However pairwise comparisons indicated that the Q.PS and Q.PS.Pro kits had more

442 significant differences amongst distances. Despite a similar trend amongst the kits, there were

443 distinct differences in the relative abundance of taxa. This suggests that there are likely to be

444 taxon-specific variations in cell lysis between the kits, especially in the eukaryotic dataset. This

445 finding is in agreement with other studies that have found a similar trend (Carrigg et al., 2007;

446 Lekang, Thompson \& Troedsson, 2015; Ramírez, Graham \& D'Hondt, 2018). This could be

447 further tested by using positive extraction controls such as a known mock prokaryotic

448 community, allowing for the assessment of lysis efficiencies amongst kits (Hermans, Buckley \&

449 Lear, 2018). In terms of marine monitoring of prokaryotes, the differential lysis of particular

450 groups could affect the classification of samples if taxonomic approaches such as the

451 microgAMBI or Indicator Values (IndVal) are to be used (Aylagas et al., 2017; Borja, 2018). For

452 example, in this dataset Flavobacteriaceae have higher relative abundances in the QIA2, FAV2

453 and FAV5 kits. This family is classified as tolerant to pollution in the microgAMBI and

454 substantial differences in the relative abundances between kits may impact the conclusions from

455 taxonomy-based approaches. Differences in taxonomy could also further impact conclusions that

456 are based on inferring function based on taxonomic composition using molecular approaches

457 such as Paprica (Bowman \& Ducklow, 2015; Laroche et al., 2018). For the eukaryotic dataset the

458 DNA sample will combine a complex mix of extracellular DNA released by macrofaunal

459 organisms, DNA from living organisms (ranging from microeukaryotes up to meiofauna and

460 larger depending on sample size), and fragments of dead organisms. Interestingly, Conoidasida,

461 Novel Apicomplexa Class I and Syndinales are parasitic taxa of invertebrate and vertebrate

462 macro-organism. In the case of Conoidasida and Syndiniales these taxa were more abundant in

463 the kits using larger weights of sediment. This may be due to the fact that these larger weights of

464 sediment would have increased probabilities to sample specimens or fragments of these larger

465 organisms which occur at lower densities in the sediment. 
467 More recently, de novo approaches such as b-MBI and e-MBI which work at the ASV level have

468 been developed to assess marine ecosystem health without the restraint of relying on taxonomic

469 classifications (Keeley, Wood \& Pochon, 2018). Multivariate analysis of these de novo

470 approaches indicated that there was a significant difference in the proportion of ASVs assigned

471 to each eco-group. However, pairwise comparisons showed that there was no significant pairwise

472 comparisons amongst the kits and, in similarity with the community composition, the organic

473 enrichment gradient observed with distance from the farm was a stronger determinant of the

474 resulting assessment of health. This suggests that the type of kit used will have limited impact on

475 the management decisions obtained across defined ecological gradients.

476

477 Conclusions

478

479 Extracted DNA from commercial kits should be of high quantity and provide a repeatable

480 representation of the community in a sample. In this study, we showed that all investigated kits

481 showed a similar pattern of community change along the disturbance gradient away from the fish

482 farm pens, and that the inferred metabarcoding-based biotic indices were also similar amongst

483 kits. This indicated that the organic enrichment gradient had a higher impact on prokaryotic and

484 eukaryotic composition and biotic indices than any individual extraction kit. Further, only a

485 small percentage of ASVs were shared between all kits in both the prokaryotic and eukaryotic

486 datasets. However, these shared ASVs accounted for a substantial amount of total read number,

487 suggesting that the core communities were captured in the DNA extracted by all kits.

488 Nevertheless, while lower overall quantities of DNA were obtained from the Qiagen Power Soil

489 (Q.PS) and Qiagen Power Soil Pro (Q.PS.Pro) kits, likely due to the lower volume of sediment

490 used, the quality of the extracted DNA was higher. This could lead to less inhibition in the

491 proceeding PCR steps. The Q.PS and Q.PS.Pro also had the highest number of unique ASVs.

492

493 In conclusion, we advocate for the use of the Q.PS.Pro kit for sampling prokaryotic and

494 eukaryotic communities in marine benthic environments associated with marine aquaculture.

495 While the Q.PS and Q.PS.Pro kit had similar results, the recent discontinuation of the former kit

496 rules out the use of this kit in the future. We base this conclusion on the higher DNA quality

497 values and richness achieved with this kit. 


\section{Acknowledgments}

500 We thank New Zealand King Salmon Co. Limited, for access to their farms, samples and in-kind 501 support. We are also grateful to Olivia Johnson, Deanna Elvines, Lauren Fletcher, Holly Bennett, 502 and Emily McGrath (Cawthron) for their help in collecting the molecular samples. This research 503 was supported by multiple agencies, including (in reducing order of contribution): New Zealand 504 Seafood Innovation Limited (contract 1804), New Zealand King Salmon Co. Limited, Cawthron 505 Institute Internal Investment Fund, the New Zealand Ministry for Primary Industry, and the 506 Marlborough District Council. We would also like to thank the editor Dr. Owen Wangensteen as 507 well as the reviewer Dr. Reindert Nijland and another anonymous reviewer for their time and 508 consideration in improving this manuscript.

\section{References}

Aguado-Giménez F, Gairín JI, Martinez-Garcia E, Fernandez-Gonzalez V, Ballester Moltó M, Cerezo-Valverde J, Sanchez-Jerez P. 2015. Application of "taxocene surrogation" and "taxonomic sufficiency" concepts to fish farming environmental monitoring. Comparison of BOPA index versus polychaete assemblage structure. Marine Environmental Research 103:27-35. DOI: 10.1016/j.marenvres.2014.10.006. and visualise $16 S$ rRNA amplicon data. Statisticl Methods. Primer-E Limited. optimized method for the extraction of ancient eukaryote DNA from marine sediments. Molecular Ecology Resources 20:906-919. DOI: 10.1111/1755-0998.13162. 
527 Aylagas E, Borja A, Pochon X, Zaiko A, Keeley N, Bruce K, Hong P, Ruiz GM, Stein ED,

528 Theroux S, Geraldi N, Ortega A, Gajdzik L, Coker DJ, Katan Y, Hikmawan T, Saleem A,

529 Alamer S, Jones BH, Duarte CM, Pearman J, Carvalho S. 2020. Translational Molecular

530 Ecology in practice: Linking DNA-based methods to actionable marine environmental management. Science of The Total Environment 744:140780. DOI: 10.1016/j.scitotenv.2020.140780.

Aylagas E, Borja Á, Tangherlini M, Dell'Anno A, Corinaldesi C, Michell CT, Irigoien X, Danovaro R, Rodríguez-Ezpeleta N. 2017. A bacterial community-based index to assess the ecological status of estuarine and coastal environments. Marine Pollution Bulletin 114:679-688.

Bell KL, Burgess KS, Botsch JC, Dobbs EK, Read TD, Brosi BJ. 2019. Quantitative and qualitative assessment of pollen DNA metabarcoding using constructed species mixtures. Molecular Ecology 28:431-455. DOI: 10.1111/mec.14840.

Bohmann K, Evans A, Gilbert MT, Carvalho GR, Creer S, Knapp M, Yu DW, de Bruyn M. 2014. Environmental DNA for wildlife biology and biodiversity monitoring. Trends Ecol Evol 29:358-67. DOI: 10.1016/j.tree.2014.04.003. EJ, Arumugam M, Asnicar F, Bai Y, Bisanz JE, Bittinger K, Brejnrod A, Brislawn CJ, Brown CT, Callahan BJ, Caraballo-Rodríguez AM, Chase J, Cope EK, Silva RD, Diener C, Dorrestein PC, Douglas GM, Durall DM, Duvallet C, Edwardson CF, Ernst M, Estaki M, Fouquier J, Gauglitz JM, Gibbons SM, Gibson DL, Gonzalez A, Gorlick K, Guo J, Hillmann B, Holmes S, Holste H, Huttenhower C, Huttley GA, Janssen S, Jarmusch AK, Jiang L, Kaehler BD, Kang KB, Keefe CR, Keim P, Kelley ST, Knights D, Koester I, 
Kosciolek T, Kreps J, Langille MGI, Lee J, Ley R, Liu Y-X, Loftfield E, Lozupone C,

551

552

553

554

555

556

557

558

559

560

561

562

563

564

565

566

567

568

569

570

571

572 Maher M, Marotz C, Martin BD, McDonald D, McIver LJ, Melnik AV, Metcalf JL, Morgan SC, Morton JT, Naimey AT, Navas-Molina JA, Nothias LF, Orchanian SB, Pearson T, Peoples SL, Petras D, Preuss ML, Pruesse E, Rasmussen LB, Rivers A, Robeson MS, Rosenthal P, Segata N, Shaffer M, Shiffer A, Sinha R, Song SJ, Spear JR, Swafford AD, Thompson LR, Torres PJ, Trinh P, Tripathi A, Turnbaugh PJ, Ul-Hasan S, Hooft JJJ van der, Vargas F, Vázquez-Baeza Y, Vogtmann E, Hippel M von, Walters W, Wan Y, Wang M, Warren J, Weber KC, Williamson CHD, Willis AD, Xu ZZ, Zaneveld JR, Zhang Y, Zhu Q, Knight R, Caporaso JG. 2019. Reproducible, interactive, scalable and extensible microbiome data science using QIIME 2. Nature Biotechnology 37:852857. DOI: $10.1038 / \mathrm{s} 41587-019-0209-9$.

Borja A. 2018. Testing the efficiency of a bacterial community-based index (microgAMBI) to assess distinct impact sources in six locations around the world. Ecological Indicators $85: 594-602$.

Bowman JS, Ducklow HW. 2015. Microbial communities can be described by metabolic structure: A general framework and application to a seasonally variable, depth-stratified microbial community from the coastal West Antarctic Peninsula. PloS one 10:e135868.

Brooks KM, Mahnken CVW. 2003a. Interactions of Atlantic salmon in the Pacific northwest environment: II. Organic wastes. Fisheries Research 62:255-293. DOI: 10.1016/S01657836(03)00064-X.

Brooks KM, Mahnken CVW. 2003b. Interactions of Atlantic salmon in the Pacific Northwest environment: III. Accumulation of zinc and copper. Fisheries Research 62:295-305. DOI: 10.1016/S0165-7836(03)00065-1. 
573 Callahan BJ, McMurdie PJ, Rosen MJ, Han AW, Johnson AJA, Holmes SP. 2016. DADA2:

574 high-resolution sample inference from Illumina amplicon data. Nature methods 13:581.

575 Carrigg C, Rice O, Kavanagh S, Collins G, O'Flaherty V. 2007. DNA extraction method affects

576 microbial community profiles from soils and sediment. Applied Microbiology and

577 Biotechnology 77:955-964. DOI: 10.1007/s00253-007-1219-y.

578 Chen H, Boutros PC. 2011. VennDiagram: a package for the generation of highly-customizable 579 Venn and Euler diagrams in R. BMC bioinformatics 12:35.

580 Cordier T. 2020. Bacterial communities' taxonomic and functional turnovers both accurately 581 predict marine benthic ecological quality status. Environmental DNA 2:175-183. DOI: 10.1002/edn3.55.

583 584

Darling JA, Pochon X, Abbott CL, Inglis GJ, Zaiko A. 2020. The risks of using molecular biodiversity data for incidental detection of species of concern. Diversity and Distributions 9:1116-21. DOI: 10.1111/ddi.13108.

Dell'Anno A, Mei ML, Ianni C, Danovaro R. 2003. Impact of bioavailable heavy metals on bacterial activities in coastal marine sediments. World Journal of Microbiology and Biotechnology 19:93-100. DOI: 10.1023/A:1022581632116.

Dell'Anno A, Stefano B, Danovaro R. 2002. Quantification, base composition, and fate of extracellular DNA in marine sediments. Limnology and Oceanography 47:899-905. DOI: 10.4319/1o.2002.47.3.0899.

Dowle E, Pochon X, Keeley N, Wood SA. 2015. Assessing the effects of salmon farming seabed enrichment using bacterial community diversity and high-throughput sequencing. FEMS microbiology ecology 91:fiv089. DOI: 10.1093/femsec/fiv089. 
595 Fodelianakis S, Papageorgiou N, Karakassis I, Ladoukakis ED. 2015. Community structure

596 changes in sediment bacterial communities along an organic enrichment gradient

597 associated with fish farming. Annals of Microbiology 65:331-338. DOI: 10.1007/s13213-

$598 \quad 014-0865-4$

599 Frühe L, Cordier T, Dully V, Breiner H-W, Lentendu G, Pawlowski J, Martins C, Wilding TA,

600 Stoeck T. 2020. Supervised machine learning is superior to indicator value inference in

601 monitoring the environmental impacts of salmon aquaculture using eDNA metabarcodes.

602 Molecular Ecology n/a. DOI: 10.1111/mec.15434.

603 Haile J. 2012. Ancient DNA extraction from soils and sediments. Methods in Molecular Biology

604 (Clifton, N.J.) 840:57-63. DOI: 10.1007/978-1-61779-516-9_8.

605 He SM, Wurtzel O, Singh K, Froula JL, Yilmaz S, Tringe SG, Wang Z, Chen F, Lindquist EA,

606 Sorek R, Hugenholtz P. Validation of two ribosomal RNA removal methods for

607 microbial metatranscriptomics. Nature methods 7:807-U58. DOI: 10.1038/nmeth.1507.

608 Herlemann DP, Labrenz M, Jürgens K, Bertilsson S, Waniek JJ, Andersson AF. 2011.

609 Transitions in bacterial communities along the $2000 \mathrm{~km}$ salinity gradient of the Baltic

610 Sea. The ISME Journal 5:1571-1579. DOI: 10.1038/ismej.2011.41.

611 Hermans SM, Buckley HL, Lear G. 2018. Optimal extraction methods for the simultaneous

612 analysis of DNA from diverse organisms and sample types. Molecular Ecology

613 Resources 18:557-569. DOI: 10.1111/1755-0998.12762.

614 Holben WE, Jansson JK, Chelm BK, Tiedje JM. 1988. DNA Probe Method for the Detection of

615 Specific Microorganisms in the Soil Bacterial Community. Applied and Environmental

$616 \quad$ Microbiology 54:703-711. 
617 Holmsgaard PN, Norman A, Hede SChr, Poulsen PHB, Al-Soud WA, Hansen LH, Sørensen SJ.

618 2011. Bias in bacterial diversity as a result of Nycodenz extraction from bulk soil. Soil

619 Biology and Biochemistry 43:2152-2159. DOI: 10.1016/j.soilbio.2011.06.019.

620 Jones FC. 2008. Taxonomic sufficiency: The influence of taxonomic resolution on freshwater

621 bioassessments using benthic macroinvertebrates. Environmental Reviews 16:45-69.

622 DOI: $10.1139 / \mathrm{A} 07-010$.

623 Kallmeyer J, Smith DC. 2009. An improved electroelution method for separation of DNA from

624 humic substances in marine sediment DNA extracts. FEMS microbiology ecology

625 69:125-131. DOI: 10.1111/j.1574-6941.2009.00684.x.

626 Kandlikar GS, Gold ZJ, Cowen MC, Meyer RS, Freise AC, Kraft NJB, Moberg-Parker J,

627 Sprague J, Kushner DJ, Curd EE. 2018. ranacapa: An R package and Shiny web app to

628 explore environmental DNA data with exploratory statistics and interactive

629 visualizations. F1000Research 7. DOI: 10.12688/f1000research.16680.1.

630 Keeley NB, Forrest BM, Crawford C, Macleod CK. 2012. Exploiting salmon farm benthic

631 enrichment gradients to evaluate the regional performance of biotic indices and

632 environmental indicators. Ecological Indicators 23:453-466. DOI:

$633 \quad$ 10.1016/j.ecolind.2012.04.028.

634 Keeley NB, Forrest BM, Macleod CK. 2013. Novel observations of benthic enrichment in

635 contrasting flow regimes with implications for marine farm monitoring and management.

636 Marine Pollution Bulletin 66:105-116. DOI: 10.1016/j.marpolbul.2012.10.024.

637 Keeley NB, Macleod CK, Forrest BM. 2012. Combining best professional judgement and

638 quantile regression splines to improve characterisation of macrofaunal responses to

639 enrichment. Ecological Indicators 12:154-166. DOI: 10.1016/j.ecolind.2011.03.022. 
640 Keeley N, Wood SA, Pochon X. 2018. Development and preliminary validation of a multi641 trophic metabarcoding biotic index for monitoring benthic organic enrichment. 642 Ecological Indicators 85:1044-1057. DOI: 10.1016/j.ecolind.2017.11.014.

643 Klindworth A, Pruesse E, Schweer T, Peplies J, Quast C, Horn M, Gloeckner FO. 2013. 644 Evaluation of general 16S ribosomal RNA gene PCR primers for classical and next645 generation sequencing-based diversity studies. Nucleic Acids Research 41. DOI: 10.1093/nar/gks808.

647 Knauth S, Schmidt H, Tippkötter R. 2013. Comparison of commercial kits for the extraction of DNA from paddy soils. Letters in Applied Microbiology 56:222-228. DOI: 10.1111/lam.12038.

Lakay FM, Botha A, Prior BA. 2007. Comparative analysis of environmental DNA extraction 651 and purification methods from different humic acid-rich soils. Journal of Applied Microbiology 102:265-273. DOI: 10.1111/j.1365-2672.2006.03052.x.

Lanzén A, Lekang K, Jonassen I, Thompson EM, Troedsson C. 2017. DNA extraction replicates improve diversity and compositional dissimilarity in metabarcoding of eukaryotes in marine sediments. PLoS ONE 12. DOI: 10.1371/journal.pone.0179443.

Laroche O, Pochon X, Tremblay LA, Ellis JI, Lear G, Wood SA. 2018. Incorporating molecularbased functional and co-occurrence network properties into benthic marine impact assessments. FEMS Microbiology Ecology 94. DOI: 10.1093/femsec/fiy167.

Laroche O, Wood SA, Tremblay LA, Ellis JI, Lejzerowicz F, Pawlowski J, Lear G, Atalah J, 660 Pochon X. 2016. First evaluation of foraminiferal metabarcoding for monitoring 661 environmental impact from an offshore oil drilling site. Marine Environmental Research 662 120:225-235. DOI: 10.1016/j.marenvres.2016.08.009. 
663 Lear G, Dickie I, Banks J, Boyer S, Buckley H, Buckley T, Cruickshank R, Dopheide A,

664 Handley K, Hermans S, Kamke J, Lee C, Macdiarmid R, Morales S, Orlovich D, Smissen

665 R, Wood J, Holdaway R. 2018. Methods for the extraction, storage, amplification and

666 sequencing of DNA from environmental samples. New Zealand Journal of Ecology

667 42:10. DOI: $10.20417 /$ nzjecol.42.9.

Lejzerowicz F, Esling P, Pillet L, Wilding TA, Black KD, Pawlowski J. 2015. High-throughput sequencing and morphology perform equally well for benthic monitoring of marine ecosystems. Scientific Reports 5. DOI: 10.1038/srep13932.

Lekang K, Thompson EM, Troedsson C. 2015. A comparison of DNA extraction methods for biodiversity studies of eukaryotes in marine sediments. Aquatic Microbial Ecology 75:15-25. DOI: 10.3354/ame01741.

Lever MA, Torti A, Eickenbusch P, Michaud AB, Šantl-Temkiv T, Jørgensen BB. 2015. A modular method for the extraction of DNA and RNA, and the separation of DNA pools from diverse environmental sample types. Frontiers in Microbiology 6. DOI: 10.3389/fmicb.2015.00476.

Levy-Booth DJ, Campbell RG, Gulden RH, Hart MM, Powell JR, Klironomos JN, Pauls KP, Swanton CJ, Trevors JT, Dunfield KE. 2007. Cycling of extracellular DNA in the soil environment. Soil Biology and Biochemistry 39:2977-2991. DOI:

681 10.1016/j.soilbio.2007.06.020.

682 Lloyd KG, Macgregor BJ, Teske A. 2010. Quantitative PCR methods for RNA and DNA in 683 marine sediments: maximizing yield while overcoming inhibition. FEMS microbiology 684 ecology 72:143-151. DOI: 10.1111/j.1574-6941.2009.00827.x. 
685 Luna GM, Dell'Anno A, Danovaro R. 2006. DNA extraction procedure: a critical issue for 686 bacterial diversity assessment in marine sediments. Environmental Microbiology 8:308687 320. DOI: $10.1111 /$ j.1462-2920.2005.00896.x.

688 Lynch MD, Neufeld JD. 2015. Ecology and exploration of the rare biosphere. Nature Reviews $689 \quad$ Microbiology 13:217.

690 MacGregor BJ, Moser DP, Alm EW, Nealson KH, Stahl DA. 1997. Crenarchaeota in Lake 691 Michigan sediment. Applied and Environmental Microbiology 63:1178-1181.

692 Martin M. 2011. Cutadapt removes adapter sequences from high-throughput sequencing reads.

693 EMBnet.journal 17:10-12. DOI: 10.14806/ej.17.1.200.

694

695

696

697

698

699

700

701

702

703

704 705

McKee AM, Spear SF, Pierson TW. 2015. The effect of dilution and the use of a post-extraction nucleic acid purification column on the accuracy, precision, and inhibition of environmental DNA samples. Biological Conservation 183:70-76. DOI: 10.1016/j.biocon.2014.11.031.

McMurdie PJ, Holmes S. 2013. phyloseq: An R package for reproducible interactive analysis and graphics of microbiome census data. PloS one 8:e61217. DOI: 10.1371/journal.pone.0061217.

Morono Y, Terada T, Hoshino T, Inagaki F. 2014. Hot-Alkaline DNA Extraction Method for Deep-Subseafloor Archaeal Communities. Applied and Environmental Microbiology 80:1985-1994. DOI: 10.1128/AEM.04150-13.

MPI. 2018. Best Management Practice guidelines for salmon farms inthe Marlborough Sounds. Fisheries New Zealand. 
706 Papageorgiou N, Sigala K, Karakassis I. 2009. Changes of macrofaunal functional composition

707 at sedimentary habitats in the vicinity of fish farms. Estuarine, Coastal and Shelf Science

708 83:561-568. DOI: 10.1016/j.ecss.2009.05.002.

709 Pawlowski J, Esling P, Lejzerowicz F, Cedhagen T, Wilding TA. 2014. Environmental

710 monitoring through protist next-generation sequencing metabarcoding: assessing the

711 impact of fish farming on benthic foraminifera communities. Molecular Ecology

712 Resources 14:1129-1140. DOI: 10.1111/1755-0998.12261.

713 Pawlowski J, Esling P, Lejzerowicz F, Cordier T, Visco J, Martins C, Kvalvik A, Staven K,

714 Cedhagen T. 2016a. Benthic monitoring of salmon farms in Norway using foraminiferal

715 metabarcoding. Aquaculture Environment Interactions 8:371-386. DOI:

$716 \quad 10.3354 /$ aei00182.

717 Pawlowski J, Lejzerowicz F, Apotheloz-Perret-Gentil L, Visco J, Esling P. 2016b. Protist metabarcoding and environmental biomonitoring: Time for change. European Journal of Protistology 55:12-25. DOI: 10.1016/j.ejop.2016.02.003.

Pearman JK, Kurten S, Sarma YVB, Jones B, Carvalho S. 2016. Biodiversity patterns of plankton assemblages at the extremes of the Red Sea. FEMS Microbiol Ecol 92. DOI: 10.1093/femsec/fiw002.

723 $7249: 191-197$.

Pedros-Alio C. 2006. Genomics and marine microbial ecology. International Microbiology

725 Pitcher DG, Saunders NA, Owen RJ. 1989. Rapid extraction of bacterial genomic DNA with 726 guanidium thiocyanate. Letters in Applied Microbiology 8:151-156. DOI:

727 10.1111/j.1472-765X.1989.tb00262.x. 
728 Pochon X, Wood SA, Atalah J, Laroche O, Zaiko A, Keeley NB. 2020. A validated protocol for

729 benthic monitoring of New Zealand's salmon farms using environmental DNA. Prepared

730 for Seafood Innovation Ltd, New Zealand King Salmon Company Ltd, Ministry for

731 Primary Industries and Marlborough District Council. Nelson, New Zealand: Cawthron

732 Institute.

733 Pochon X, Wood SA, Keeley NB, Lejzerowicz F, Esling P, Drew J, Pawlowski J. 2015.

734 Accurate assessment of the impact of salmon farming on benthic sediment enrichment

735 using foraminiferal metabarcoding. Marine Pollution Bulletin 100:370-382. DOI:

$736 \quad$ 10.1016/j.marpolbul.2015.08.022.

737 Pruesse E, Quast C, Knittel K, Fuchs BM, Ludwig W, Peplies J, Gloeckner FO. 2007. SILVA: a

738 comprehensive online resource for quality checked and aligned ribosomal RNA sequence

739 data compatible with ARB. Nucleic Acids Research 35:7188-7196. DOI:

$740 \quad 10.1093 /$ nar/gkm864.

741 Ramírez GA, Graham D, D’Hondt S. 2018. Influence of commercial DNA extraction kit choice on prokaryotic community metrics in marine sediment. Limnology and Oceanography:

744 Rees HC, Maddison BC, Middleditch DJ, Patmore JRM, Gough KC, Crispo E. 2014. REVIEW: The detection of aquatic animal species using environmental DNA - a review of eDNA as a survey tool in ecology. Journal of applied ecology.

Snelgrove PVR. 1997. The importance of marine sediment biodiversity in ecosystem processes. Ambio 26:578-583.

Stoeck T, Frühe L, Forster D, Cordier T, Martins CIM, Pawlowski J. 2018a. Environmental DNA metabarcoding of benthic bacterial communities indicates the benthic footprint of 
salmon aquaculture. Marine Pollution Bulletin 127:139-149. DOI:

752 10.1016/j.marpolbul.2017.11.065.

753 Stoeck T, Kochems R, Forster D, Lejzerowicz F, Pawlowski J. 2018b. Metabarcoding of benthic ciliate communities shows high potential for environmental monitoring in salmon aquaculture. Ecological Indicators 85:153-164. DOI: 10.1016/j.ecolind.2017.10.041.

Taberlet P, Bonin A, Zinger L, Coissac E. 2018. Environmental DNA: For Biodiversity Research 757 and Monitoring. Oxford University Press.

Team RC. 2020. R: A language and environment for statistical computing. Vienna, Austria: R Foundation for Statistical Computing; 2014.

Torti A, Lever MA, Jørgensen BB. 2015. Origin, dynamics, and implications of extracellular DNA pools in marine sediments. Marine Genomics 24:185-196. DOI: 10.1016/j.margen.2015.08.007.

763
Verhoeven JTP, Salvo F, Knight R, Hamoutene D, Dufour SC. 2018. Temporal bacterial surveillance of salmon aquaculture sites indicates a long lasting benthic impact with minimal recovery. Frontiers in Microbiology 9. DOI: 10.3389/fmicb.2018.03054.

Wang Q, Garrity GM, Tiedje JM, Cole JR. 2007. Naive Bayesian classifier for rapid assignment of rRNA sequences into the new bacterial taxonomy. Applied and Environmental Microbiology 73:5261-5267.

Wickham H. 2016. ggplot2: elegant graphics for data analysis. Springer.

Yeates C, Gillings M, Davison A, Altavilla N, Veal D. 1998. Methods for microbial DNA extraction from soil for PCR amplification. Biological Procedures Online 1:40-47. DOI: $10.1251 /$ bpo6. 
773 Young JM, Rawlence NJ, Weyrich LS, Cooper A. 2014. Limitations and recommendations for

774 successful DNA extraction from forensic soil samples: A review. Science \& Justice

$775 \quad$ 54:238-244. DOI: 10.1016/j.scijus.2014.02.006.

776 Zhan A, Hulák M, Sylvester F, Huang X, Adebayo AA, Abbott CL, Adamowicz SJ, Heath DD,

777 Cristescu ME, MacIsaac HJ. 2013. High sensitivity of 454 pyrosequencing for detection

778 of rare species in aquatic communities. Methods in Ecology and Evolution 4:558-565.

779 
Figure 1

Figure 1: Sampling sites around the Otanerau salmon farm in the Marlborough Sounds, New Zealand

Site map indicating; (A) the location of the Otanerau salmon farm (OTA, red dot) within the Marlborough Sounds, New Zealand, and (B) the arrangement of the sampling stations with distance in relation to the OTA salmon farm. Figure modified from Dowle et al. (2015).

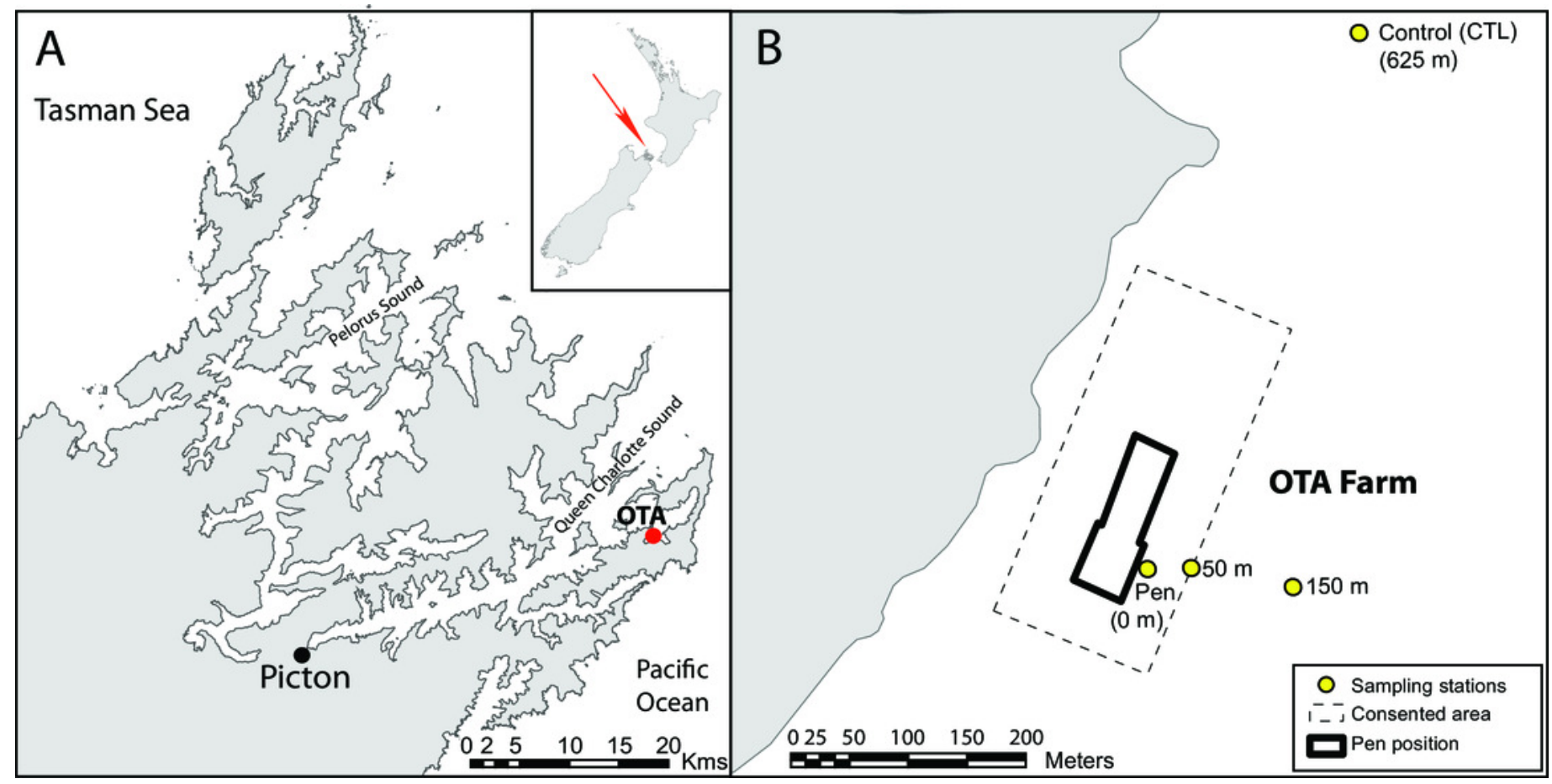


Figure 2

Figure 2: Number of amplicon sequence variants for different DNA extraction kits

Number of Amplicon Sequence Variants per kit for the eukaryotic 18S rRNA (Eukaryotes; A) gene and prokaryotic 16S rRNA (Prokaryotes; B) gene. The symbols designate the distance from the aquaculture pen. Q.PS = Qiagen Dneasy PowerSoil Kit $(0.25 \mathrm{~g})$, Q.PS.Pro = Qiagen Dneasy PowerSoil Pro Kit (0.25 g), QIA2 = Qiagen Rneasy PowerSoil Total RNA/DNA extraction/elution Kit (2 g), FAV2 = Favorgen FavorPrep Soil DNA Isolation Midi Kit (2 g), FAV5 $=$ Favorgen FavorPrep Soil DNA Isolation Midi Kit $(5 \mathrm{~g})$.

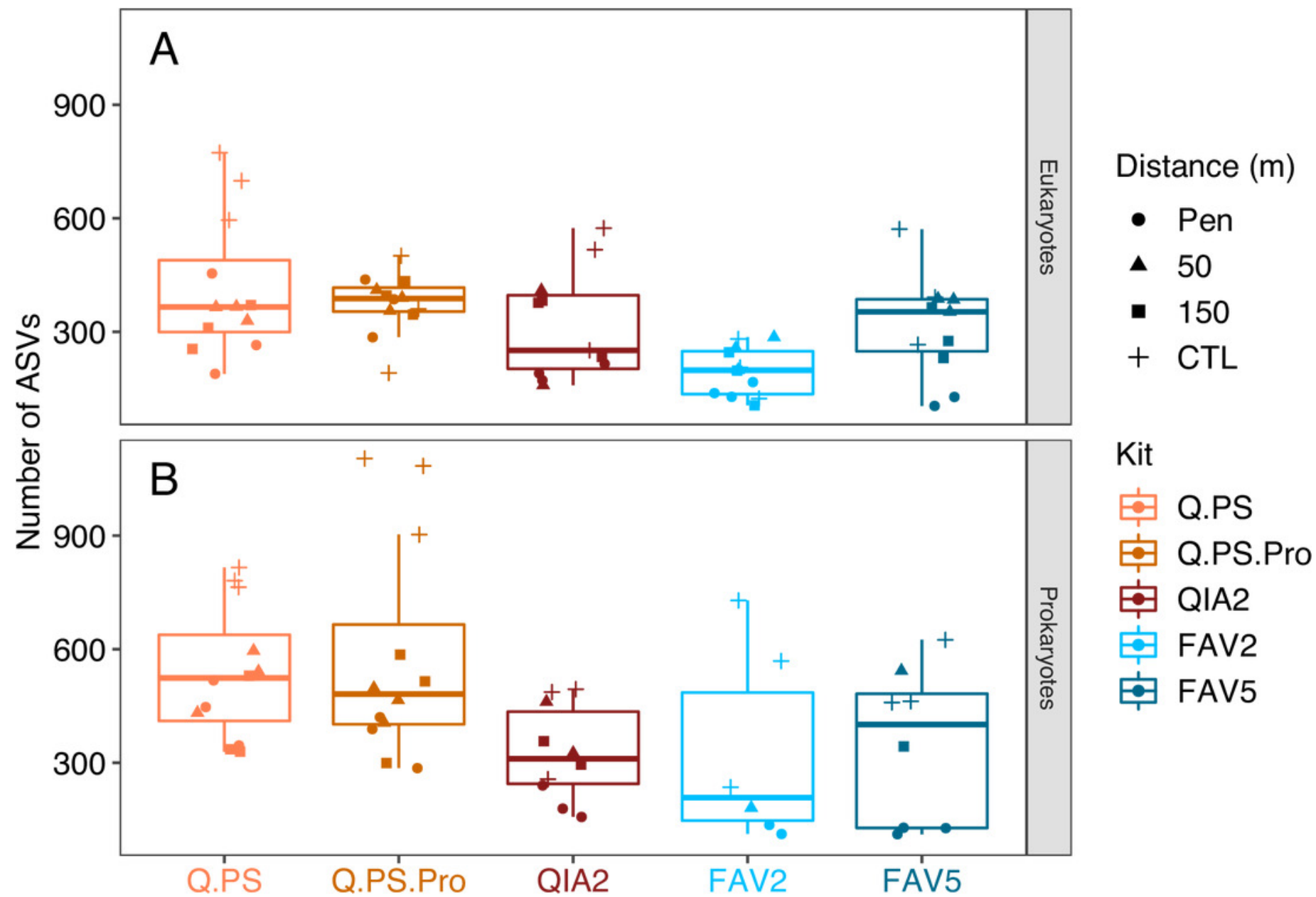




\section{Figure 3}

Figure 3: Shared amplicon sequence variants amongst kits.

Number of shared Amplicon Sequence Variants amongst kits for the; A) prokaryotic 16S rRNA gene, and B) eukaryotic 18S rRNA gene datasets. Q.PS = Qiagen Dneasy PowerSoil Kit (0.25 g), Q.PS.Pro = Qiagen Dneasy PowerSoil Pro Kit (0.25 g), QIA2 = Qiagen Rneasy PowerSoil Total RNA/DNA extraction/elution Kit (2 g), FAV2 = Favorgen FavorPrep Soil DNA Isolation Midi Kit (2 g), FAV5 = Favorgen FavorPrep Soil DNA Isolation Midi Kit (5 g).

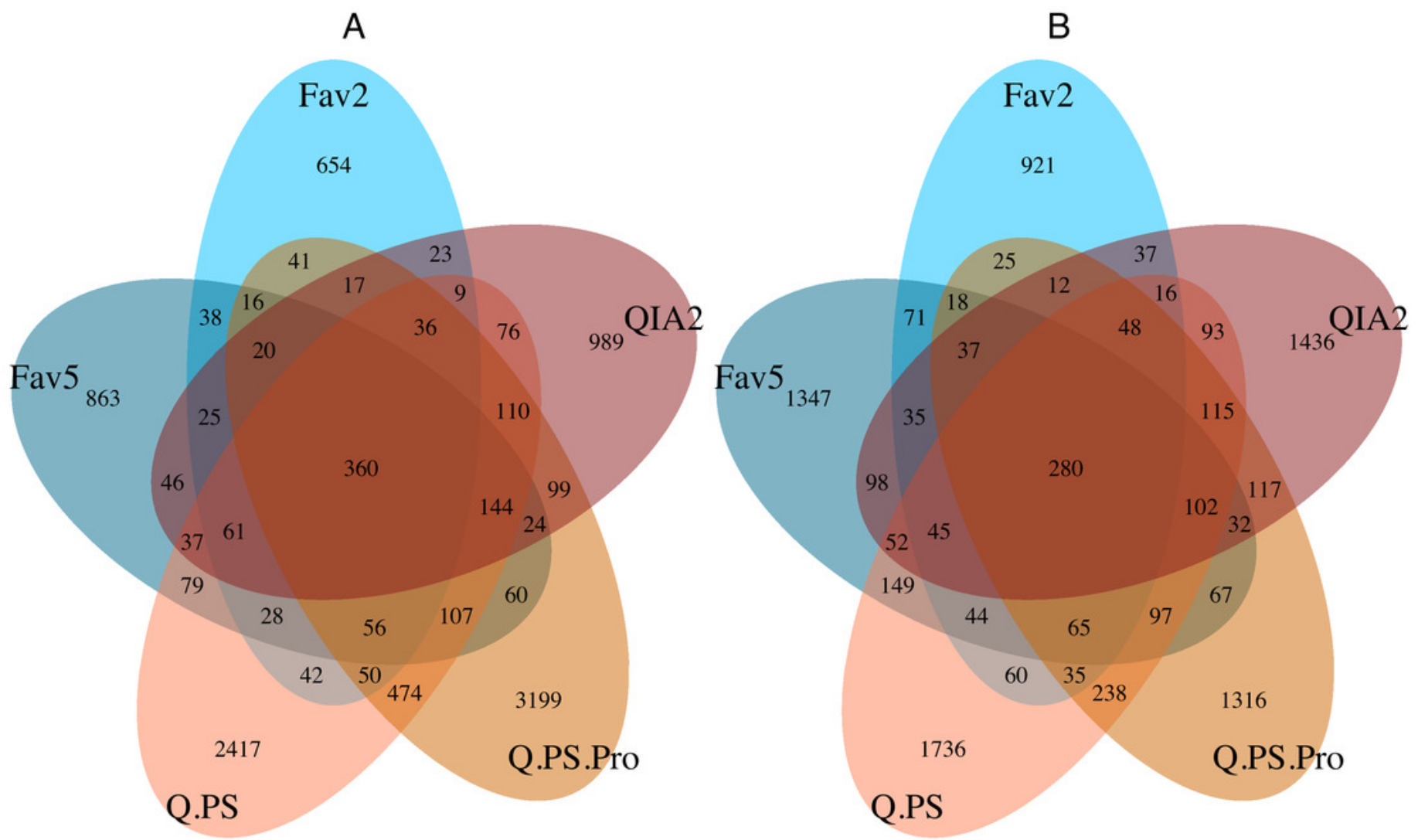




\section{Figure 4}

Figure 4: Relative abundance of sequence reads for the 10 most abundant classes.

Relative abundances (\% of sample total) of sequence reads corresponding to the ten most abundant classes of; (A) prokaryotes, and (B) eukaryotes. A complete breakdown of all classes is presented in Table S4 and Table S5. Q.PS = Qiagen Dneasy PowerSoil Kit $(0.25 \mathrm{~g})$, Q.PS.Pro = Qiagen Dneasy PowerSoil Pro Kit $(0.25 \mathrm{~g})$, QIA2 = Qiagen Rneasy PowerSoil Total RNA/DNA extraction/elution Kit (2 g), FAV2 = Favorgen FavorPrep Soil DNA Isolation Midi Kit $(2 \mathrm{~g})$, FAV5 = Favorgen FavorPrep Soil DNA Isolation Midi Kit (5 g).
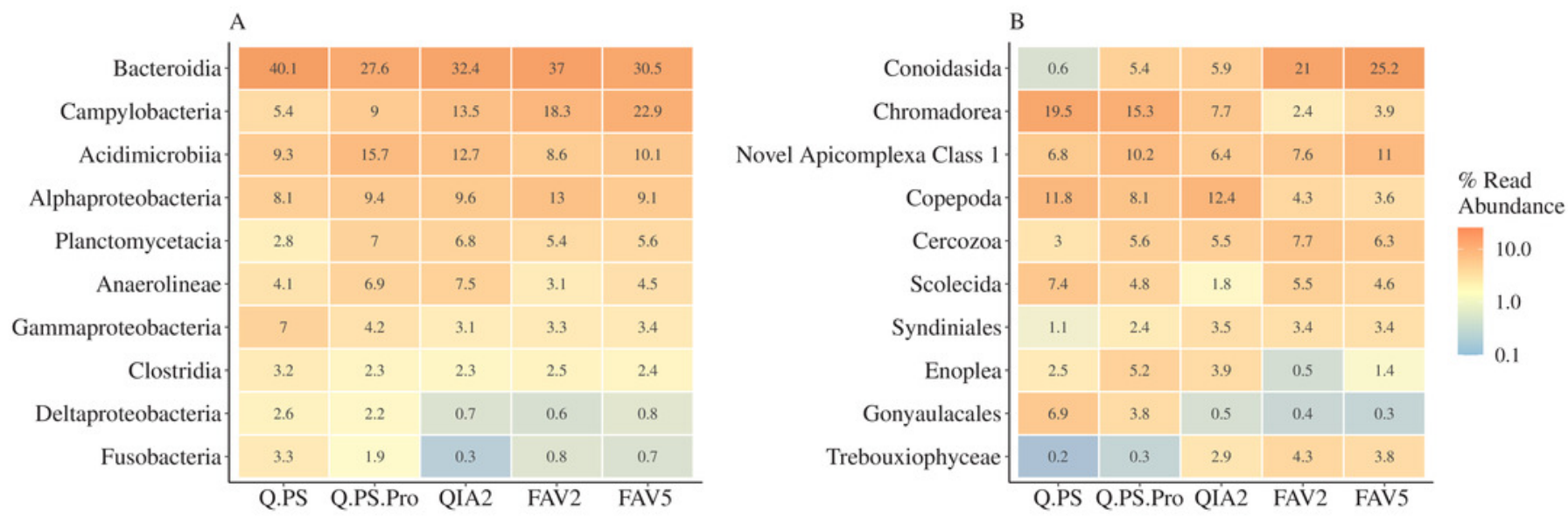


\section{Figure 5}

Figure 5: Non metric multi-dimensional scaling plots for the prokaryotic and eukaryotic community structures

Non metric multi-dimensional scaling plots depicting; (A) prokaryotic (16S rRNA gene), and (B) eukaryote (18S rRNA gene) species community structures (Bray Curtis distance matrix of square root transformed relative abundance data) across a distance gradient at Otanerau fish farm in New Zealand (2015). The plot displays the clustering of communities recovered using the five distinct DNA extraction methods. Q.PS = Qiagen Dneasy PowerSoil Kit $(0.25 \mathrm{~g})$, Q.PS.Pro = Qiagen Dneasy PowerSoil Pro Kit $(0.25 \mathrm{~g})$, QIA2 = Qiagen Rneasy PowerSoil Total RNA/DNA extraction/elution Kit $(2 \mathrm{~g})$, FAV2 = Favorgen FavorPrep Soil DNA Isolation Midi Kit $(2 \mathrm{~g})$, FAV5 $=$ Favorgen FavorPrep Soil DNA Isolation Midi Kit (5 g). Coloured icons within the plots show location of sampling site: squares (control sites), circles (150 m from pen), triangles (50 $\mathrm{m}$ from pen), crosses (pen).
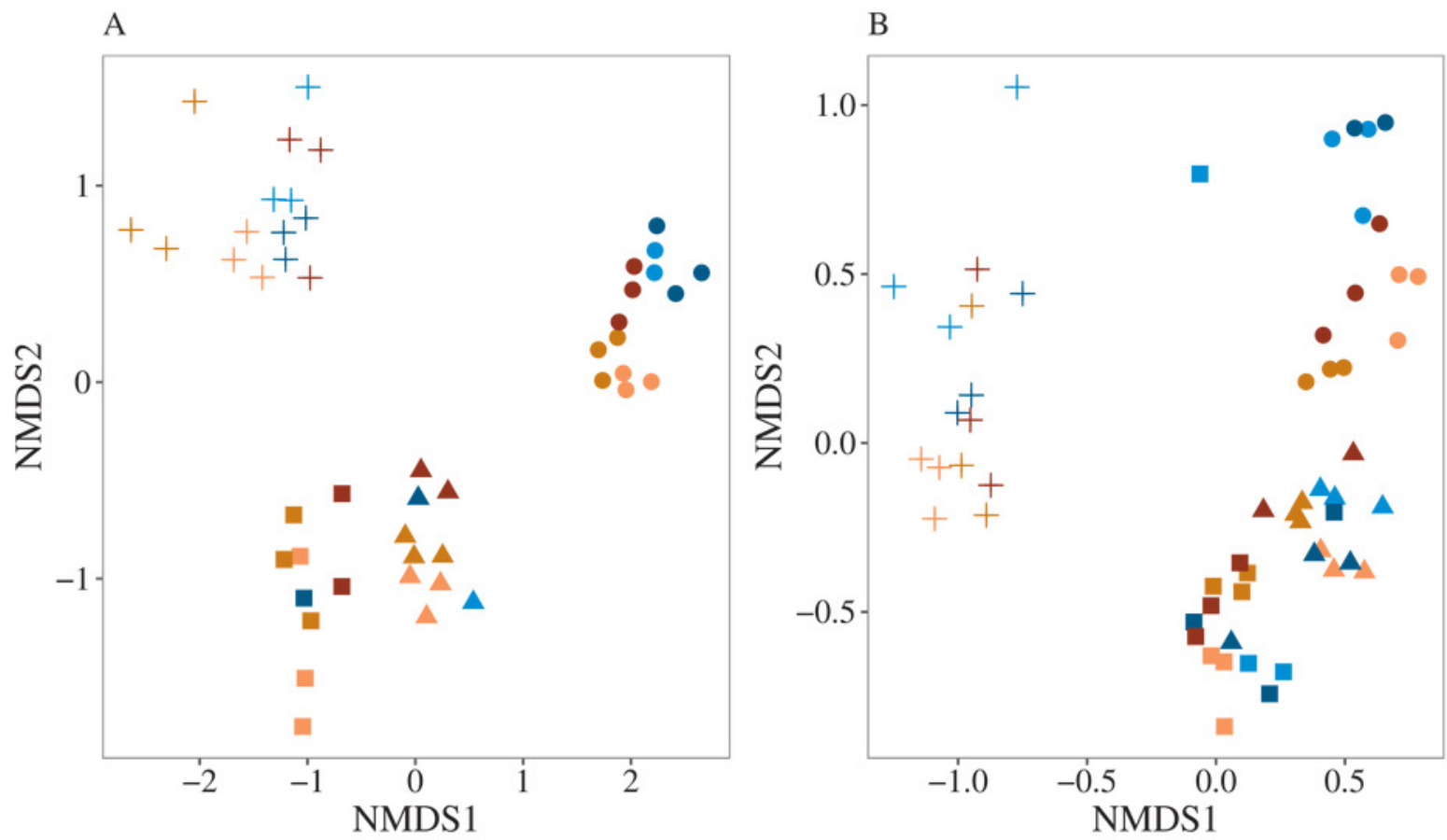

Kit

- FAV2

- FAV5

- Q.PS

- Q.PS.Pro

- QIA2

Distance (m)

- Pen

- 50

- 150

+ CTL 


\section{Figure 6}

Figure 6: Non metric multi-dimensional scaling plots of the bacterial and eukaryotic metabarcoding biotic index

Non metric multi-dimensional scaling plots depicting A) bacterial metabarcoding biotic index (b-MBI) and B) eukaryotic metabarcoding biotic index (e-MBI) (Bray Curtis distance matrix of square root transformation of weights for each eco-group) across a distance gradient at Otanerau fish farm in New Zealand (2015). Q.PS = Qiagen Dneasy PowerSoil Kit $(0.25 \mathrm{~g})$, Q.PS.Pro = Qiagen Dneasy PowerSoil Pro Kit $(0.25 \mathrm{~g})$, QIA2 = Qiagen Rneasy PowerSoil Total RNA/DNA extraction/elution Kit (2 g), FAV2 Favorgen FavorPrep Soil DNA Isolation Midi Kit (2 g), FAV5 = Favorgen FavorPrep Soil DNA Isolation Midi Kit (5 g).
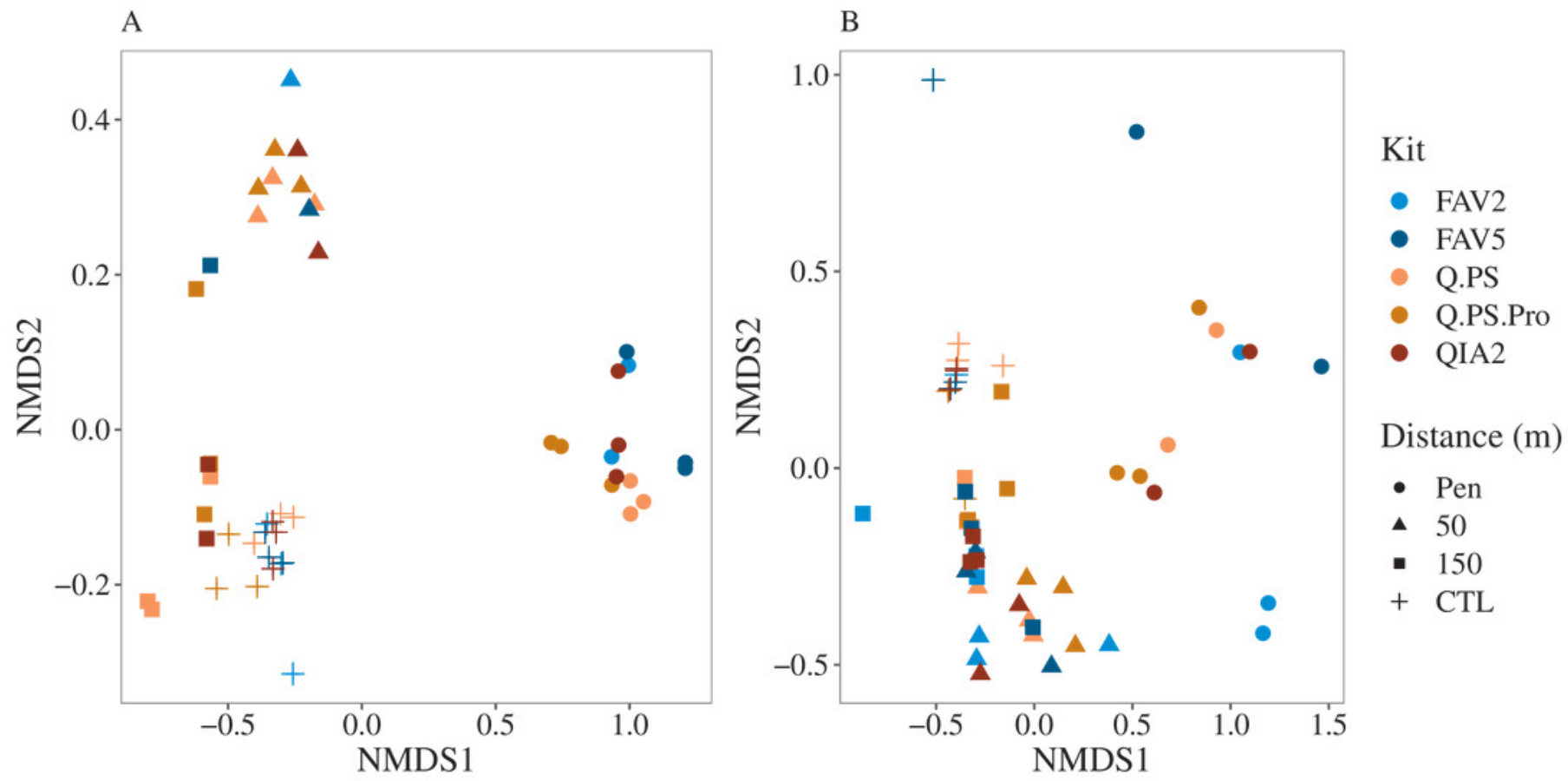


\section{Table $\mathbf{1}$ (on next page)}

Table 1: Kits used in this study and sediment weights used with each kit.

Kits used in this study and sediment weights used with each kit. 


\begin{tabular}{|l|c|c|}
\hline Kit name & $\begin{array}{c}\text { Abbreviated } \\
\text { Name }\end{array}$ & $\begin{array}{c}\text { Sediment weight } \\
(\mathrm{g})\end{array}$ \\
\hline Qiagen DNeasy PowerSoil Kit & Q.PS & 0.25 \\
\hline Qiagen DNeasy PowerSoil Pro Kit & Q.PS.Pro & 0.25 \\
\hline Qiagen RNeasy PowerSoil Total RNA/DNA extraction/elution Kit & QIA2 & 2 \\
\hline Favorgen FavorPrep Soil DNA Isolation Midi Kit & FAV2 & 2 \\
\hline Favorgen FavorPrep Soil DNA Isolation Midi Kit & FAV5 & 5 \\
\hline
\end{tabular}

